\title{
Development of Safe and Effective Indigenous Intensive Care Unit Ventilators for COVID-19 Pandemic
}

\author{
Anup Daniel Varghese, Sanjay Orathi Patangi', Kumar G. Belani², Muralidhar Kanchi \\ Departments of Critical Care, ${ }^{I}$ Intensive Care and ${ }^{3}$ Anaesthesia and Intensive Care, Narayana Institute of Cardiac Sciences, Narayana Health City, Bengaluru, \\ Karnataka, India, ${ }^{2}$ Department of Anaesthesiology, M Health Fairview, University of Minnesota Masonic Children's Hospital, Minneapolis, MN, USA
}

\section{Abstract}

Severe acute respiratory syndrome-coronavirus 2 has spread rapidly worldwide infecting $\geq 4$ million people including $\geq 2.9$ million deaths and overwhelming health-care systems globally. It has prompted governments to open field medical facilities to decongest hospitals and triage patients. Governments are preparing for a stage 3 surge in cases leading to a situation of "severe shortage" of mechanical ventilators due to an overwhelming number of cases. Health authorities are looking into measures for mass production of ventilators with locally available materials. However, when deploying these devices on patients, it is imperative to ascertain if they are safe and do not perpetuate a vicious circle of worsening lung injury and death. The Association for the Advancement of Medical Instrumentation and the Medicines and Healthcare Products Regulatory Agency have brought out guidelines that emergency ventilators manufactured for the current epidemic need to satisfy.

Keywords: COVID-19, critical care, pandemic, pneumonia, severe acute respiratory syndrome-coronavirus 2, ventilator

\section{INTRODUCTION}

Ever since the first cases of pneumonia were diagnosed in December, ${ }^{[1,2]}$ severe acute respiratory syndrome-coronavirus 2 (SARS-CoV2) has spread rapidly across the globe infecting over 146 million people including over 3 million deaths and overwhelming health-care systems. ${ }^{[3]}$ It has prompted governments to open field medical units to decongest hospitals and triage patients. ${ }^{[4]}$ The disease is characterized by a variety of pulmonary and extrapulmonary symptoms. While majority have mild disease, approximately 15\% have severe disease and around $5 \%$ progress to a critical state requiring respiratory support. ${ }^{[5]}$ Governments are preparing for a stage 3 surge (180\%-200\% increase) in infections ${ }^{[6]}$ leading to a situation of "severe shortage" of mechanical ventilators due to an overwhelming number of cases. This is prompting governments to reallocate precious resources ${ }^{[4,6]}$ and also check locations where mass production of ventilators with locally available materials (UK Ventilator Challenge) is possible. ${ }^{[7]}$ However, when deploying these devices on patients, it is imperative to ascertain their safety without the risk of perpetuating a vicious circle of worsening lung injury and death. This article is an attempt to review available data on essential requisites of a ventilator that can function effectively without causing further damage.

\begin{tabular}{|l|l|}
\hline \multicolumn{3}{|c|}{ Access this article online } \\
\hline Quick Response Code: & Website: \\
\hline & www.ijrc.in \\
\hline & \\
\hline
\end{tabular}

\section{COVID-19 AND THE LUNG}

Computed tomographic (CT) examination of confirmed SARS-CoV2 has found a mixed and diverse involvement of both lung parenchyma and interstitium. ${ }^{[8,9]}$ Findings can vary from predominantly peripheral involvement with ground-glass opacities in mild cases to patchy enlargement of opacities, consolidations, and "crazy paving appearance" in others. ${ }^{[8-10]}$ Often, there is a mismatch between radiological findings and clinical severity. Gattinoni et al. have described the existence of two phenotypes of COVID-19 lung, namely the Type-L and Type-H phenotypes. ${ }^{[11]}$ The most consistent clinical finding however is a severe hypoxic respiratory failure with histopathology showing diffuse alveolar damage. ${ }^{[12]}$ This heterogeneity is similar to previous descriptions of ARDS; ${ }^{[13-16]}$ hence, principles of treatment should also be similar with low tidal volume, constant driving pressure, optimum positive

Address for correspondence: Dr. Anup Daniel Varghese, Department of Critical Care, Narayana Institute of Cardiac Sciences, Narayana Health City, Bengaluru, Karnataka, India. E-mail: anup.daniel@yahoo.co.in

This is an open access journal, and articles are distributed under the terms of the Creative Commons Attribution-NonCommercial-ShareAlike 4.0 License, which allows others to remix, tweak, and build upon the work non-commercially, as long as appropriate credit is given and the new creations are licensed under the identical terms.

For reprints contact: WKHLRPMedknow_reprints@wolterskluwer.com

How to cite this article: Varghese AD, Patangi SO, Belani KG, Kanchi M. Development of safe and effective indigenous intensive care unit ventilators for COVID-19 pandemic. Indian J Respir Care 2021;10:182-9.

Received: 08-09-2020 Accepted: 02-05-2021 Published: 14-06-2021 
Varghese, et al.: ICU ventilators for COVID-19 pandemic

end-expiratory pressure (PEEP), and controlling inspiratory pressures to avoid aggravating the lung injury. ${ }^{[13,17-19]}$ All these developments point to the central role that a ventilator plays during mechanical ventilation. Hence when choosing a device for ventilation, it is mandatory that it performs as per the set parameters and not to accentuate an already damaged lung.

\section{Using Single Ventilator for Multiple Patients}

Due to the predicted shortage of ventilators to care for severely ill patients with COVID-19, ${ }^{[20]}$ several authors have described using a single ventilator to support ventilation of multiple patients. These have been demonstrated only in laboratory settings and clinical experience is sparse. ${ }^{[21-24]}$ This requires the patients to be mechanically ventilated in pressure-control mode. Their performance even under standard laboratory conditions has been dismal, hence use in diseased ARDS lungs can be dangerous. ${ }^{[24-26]}$ In addition, there is no practical experience in the published literature of connecting multiple patients in spontaneous breathing mode using a single ventilator. The authors do not recommend such a strategy due to lack of control of individual ventilation parameters which could potentially increase mortality. ${ }^{[24,26]}$ However, VESper ${ }^{\mathrm{TM}}$, a device developed by three-dimensional (3D) printing for use, as a ventilator splitter has received Food and Drug Administration (FDA) approval on an emergency basis. ${ }^{[27,28]}$ Home respirators, turbine ventilators that can function without a high-pressure oxygen source, can be deployed in an emergency for mild cases. ${ }^{[29]}$ The limitations in sharing a ventilator for two patients with respiratory failure have been expressed in a recent publication. ${ }^{[30]}$

Sourcing of ventilators from less intensive areas is a logical solution but may not be practical when the entire health-care system is overwhelmed. ${ }^{[30]}$ Availability of a standard intensive care unit (ICU) ventilator to meet ventilatory demand may be limited for several reasons. In such a situation, governments around the world are ramping up capacities to indigenously produce ventilators on an emergency basis. Standard specification for ventilators in the USA is governed by ISO 80601-2-12:2020 that establishes essential performance and basic safety requirements for ventilators and its accessories for use in adult, child, or infant patients in critical care settings within a hospital. ${ }^{[31]}$ Full compliance with accepted standards is not possible when developing new ventilators with locally available resources in such times. Given the current situation of acute ventilator shortage, governments around the world are looking for recommendations that meet "basic ventilator" standards. Regional regulators are preparing to take an informed decision during the pandemic on a case-by-case basis, as has been done in the USA recently [Figure 1]. ${ }^{[32]}$

The Association for the Advancement of Medical Instrumentation recently published guidelines for the urgent manufacturing of ventilators. ${ }^{[33]}$ Similarly, the Medicines and Healthcare Regulatory Agency (MHRA-UK) identified "minimally acceptable" technical specifications (RMVS001) for basic ventilators failing which the devices would more likely cause harm to patients. ${ }^{[34]}$ These devices are intended for short-term use to allow stabilization from a few hours extendable to a maximum of a day. In India, the Technical Committee of Defence Research and Development Organisation has been tasked by the empowered committee to identify essential specifications for ventilators to be used during the COVID-19 crisis. $^{[35]}$

\section{Basic Requirements}

Chaussier introduced a bag and mask manual ventilator in $1780{ }^{[36]}$ The concept of mechanical ventilator originated with use of the foot pump by Fell O'Dwyer in 1888. ${ }^{[36,37]}$ Starting as negative-pressure generators in the $19^{\text {th }}$ century, ventilators have progressed into the current fourth-generation machines with microprocessor controlled systems, "closed loop ventilation," and a plethora of modes. ${ }^{[36]}$ First-generation devices were modifications of the bag and mask manual ventilator (Morch ventilator, Emerson postoperative ventilator, and Engstrom ventilator). Such ventilators had only volume-control mode, no PEEP, and offered no support for spontaneous breaths and minimal alarms, monitoring or specific settings. ${ }^{[36]}$ Ventilator components can be grossly divided into a power unit, gas source, a control unit, monitors, alarms, and a breathing circuit with its accessories. ${ }^{[38-40]}$ Components are available as additional add-ons such as to warm and humidify gases.

\section{PoWer UnIT}

Ventilators need a power source to keep its components functional. They function in a controlled environment and hence are considered as Class I equipment. They also require an internal power source to continue functioning during a power failure. They need to comply with basic electrical safety as outlined in EN 60601. MHRA mandates a 20 min of battery backup and extendable to $2 \mathrm{~h}$ with swappable batteries to facilitate intrahospital transfer. ${ }^{[34]}$ Backup power source need not be integrated into the machine. An external battery source can be used for backup power to control overall size and weight. ${ }^{[33]}$

\section{Gas Supply}

Medical gas through pipelines is universally supplied at pressures between $280 \mathrm{kPa}$ and $600 \mathrm{kPa}$ and an average flow rate of $60 \mathrm{~L} / \mathrm{min}$. All modern ICU ventilators are designed to function over these ranges and use pressure regulators to further reduce the gas pressures. They also incorporate safety features to continue function during supply-related pressure drops and protect internal components from high pressure surges up to twice the maximum-rated pressure range. ${ }^{[31]}$ Ventilators that receive two gases (air and oxygen) at high pressure are regulated by flow-control valves and use a gas blender for the desired oxygen fraction. When using two high-pressure gas intakes, a mechanism to avoid the reverse 
Varghese, et al.: ICU ventilators for COVID-19 pandemic

gas leak of up to $100 \mathrm{ml} / \mathrm{h}$ during a system fault should be in place. ${ }^{[31]}$

However, during a pandemic, field hospitals may be opened to cater to a surge of patients. Such make-shift units may not have provision for a piped gas supply. Hence, ventilators developed for emergency use should be versatile to function safely using gas from cylinders.

\section{Control Unit}

On a very basic level, all ventilators need a mechanism to deliver gas in a controlled manner from source to the patient. This could be either by compressing a reservoir filled with fresh gas or controlling flows via a set of valves. A variety of drive mechanisms exist - electric motors to drive a piston, tension springs, weighted bellows, and pneumatic devices. The driving mechanism is controlled by either electronic circuit, pneumatic, or fluidic systems. Electronic circuits can be either open (no feedback control) or closed (servo-controlled; receive feedback to regulate function). Majority of modern ICU ventilators use servo-control circuits to receive monitoring data and adjust a set of inspiratory and expiratory valves to accurately deliver gas flows to the patient. Flow sensors feed back to the servo-circuit and alterations in valve regulate future breaths. This is different from closed-loop ventilation modes such as neurally adjusted ventilatory assistance, proportional assist ventilation, and others.

\section{Modes of Ventilation}

The control unit determines the ventilation modes and is the interface between the user and the machine. The software algorithm determines the ventilation mode. Ventilation mode is an algorithm that controls how the device starts (triggers), maintains, and ends (cycle) a breath during operation.

Coventorle - Courtesy of The University of Minnesota

The Coventor, a table-top sized ventilator that can be mass produced in a fraction of the time and cost of a professional-grade ventilator The design, came together in 30 days, has been shared with Boston Scientific and is being made available open source, (manufactureers around the world can copy it and put it into production as needed to combat the coronavirus pandemic).

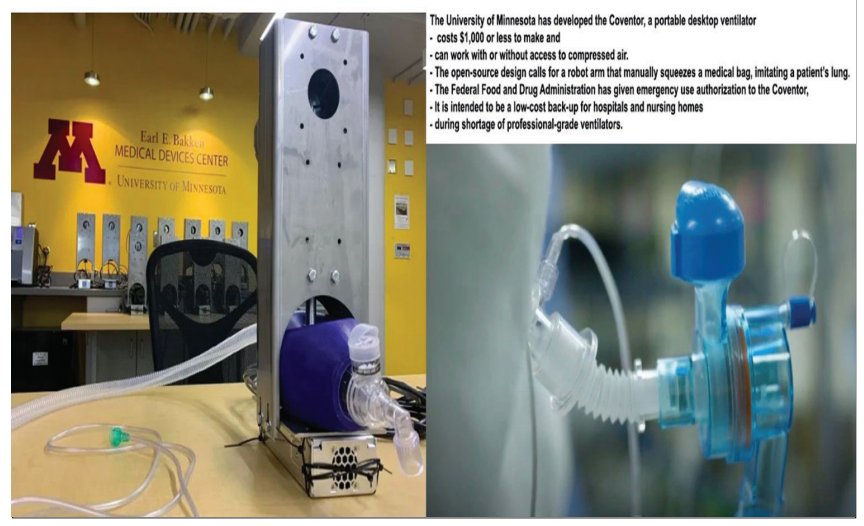

Figure 1: Dr. Stephen Richardson, a Fellow in Cardiac Anesthesiology at the University of Minnesota converted an $\mathrm{Ambu}^{\circledR}$ bag into a ventilator with the help of a team of individuals from the Institute of Engineering in Medicine
Modern ICU ventilators offer a variety of ventilation modes ranging from control (full support from the ventilator) to assist (ventilator assist spontaneous efforts of the patient). The modes are labeled according to the characteristics of trigger, cycle, and control variables. The terminology has been standardized in ISO 19223:2019. MHRA guidelines require only a single mandatory mode either volume or pressure cycled and a spontaneous mode for ventilators developed for the present emergency. ${ }^{[34]}$ In "Volume control" mode, a user-defined tidal volume is delivered during inspiration. In "Pressure control," a set pressure is maintained during the inspiratory phase. Advanced modes incorporate adaptive responses to limit pressure or achieve the desired volume. When operating in spontaneous mode, the device should sense apnea and switch to a mandatory mode. PEEP is quantified by averaging pressure in the last $50 \mathrm{~ms}$ of the expiratory phase. Acceptable leak in the system is up to $200 \mathrm{ml} / \mathrm{min}$ at $50 \mathrm{cmH} 2 \mathrm{O}$ for adult configurations, $100 \mathrm{ml} / \mathrm{min}$ for pediatric (TV between 50 and $300 \mathrm{ml}$ ) ventilators, and $50 \mathrm{ml} / \mathrm{min}$ for neonatal ventilators $(\mathrm{TV}<50 \mathrm{ml}) .{ }^{[31]}$

Ability to pause ventilation during both phases of the breathing cycle is available in most ICU ventilators. Inspiratory pauses range from $10 \mathrm{~s}$ to a maximum of $40 \mathrm{~s}$, whereas expiratory pauses are allowed for a maximum of $60 \mathrm{~s}$. However, this standard is not mandatory for ventilators developed during an emergency.

\section{Connectors}

The universal standard for connectors (ISO 5356-1:2015) on the patient end is either $15 \mathrm{~mm}$ or $22 \mathrm{~mm}$ in adult configuration and $11.5 \mathrm{~mm}$ for pediatric configuration or a coaxial $15 \mathrm{~mm} / 22 \mathrm{~mm}$ dimension. The gas exhaust ports should be $30 \mathrm{~mm}$ to enable connection to a scavenging system. These standards remain applicable for emergency use ventilators also. ${ }^{[31]}$

\section{Environmental Conditions}

All materials used for the construction of ventilator and its accessories should be free of toxins and should not leach out harmful particles into the gas pathway while in use. ${ }^{[31]}$ Ventilators are designed to function at a temperature range of $-18^{\circ} \mathrm{C}$ to $+50^{\circ} \mathrm{C}$, relative humidity of $15 \%$ to $95 \%$, and atmospheric pressure range of $70 \mathrm{kPa}$ to $110 \mathrm{kPa}$. Although relatively stationary during use, ventilators are moved around to deploy in patients and to make space for other equipment. Hence, they should be robust enough to sustain the set parameters when subjected to vibration, electromagnetic disturbances, movements, jolts, or falls. Under such circumstances, the acceptable change in parameters is within $35 \%$ of set value during inspiration, up to $25 \%$ change averaged over $1 \mathrm{~min}$ during the entire inspiratory period and PEEP changes up to 5 $\mathrm{cmH}_{2} \mathrm{O} .^{[31]}$ The user should confirm whenever settings are made outside of normal values to protect against inadvertent changes.

In a critical care environment, fluid splashes (body fluids, resuscitative fluids, blood, and products) are common 
Varghese, et al.: ICU ventilators for COVID-19 pandemic

occurrences. Ventilators should preferably be water resistant, IP22 or at least IP21 compliant for self-protection. ${ }^{[33]}$

\section{Monitoring and Alarms}

Although a wide variety of variables can be monitored by modern ventilators, a few essential ones that help in delivering safe ventilation were outlined at a consensus conference on mechanical ventilators in 1992. ${ }^{[11]}$ These include set and achieved values of pressure, flow, volume, and oxygen concentration. Whenever the variables do not fall within the accepted limits, it should result in a graded alert. Alert could be audible or visual and graded according to severity to attract attention. All alarms should be audible at a distance of at least $1 \mathrm{~m}$ and duration of pause for a maximum of $120 \mathrm{~s}$.

\section{Power failure alarm}

Ventilatory failure due to loss of power is a critical event. Hence, any power failure should activate an auditory alarm of at least $7 \mathrm{~s}$ duration. The alarm should switch to "high priority" when the internal power depletes to the final $5 \mathrm{~min}^{[31]}$

\section{Pressure}

Given the deleterious effects of high airway pressure, monitoring for high and low circuit pressure is mandatory. ${ }^{[34]}$ A "high priority" alarm activated within $200 \mathrm{~ms}$ once airway pressure exceeds the user-defined limit should draw attention of the caregiver. Modern ICU ventilators measure airway pressure relative to the patient connection port and limit it to below $60 \mathrm{cmH}_{2} \mathrm{O}$ by default. They also allow the user to extend the maximum allowable pressure to $125 \mathrm{cmH}_{2} \mathrm{O}$ in exceptional circumstances. ${ }^{[31]}$ This is to overcome the resistance of narrow tubes, in acute severe asthma or for recruitment. On activation, the device should initiate measures to reduce the airway pressure within 2 respiratory cycles or $15 \mathrm{~s}$. However, MHRA mandates measuring plateau pressure (default of $35 \mathrm{cmH}_{2} \mathrm{O}$ and max of $70 \mathrm{cmH}_{2} \mathrm{O}$ ) and peak pressures (within $2 \mathrm{cmH}_{2} \mathrm{O}$ of plateau pressure) during operation with a mechanical fail-safe if pressures exceed 80 $\mathrm{cmH}_{2} \mathrm{O} \cdot{ }^{[34]}$

The device should detect a failure in gas supply and indicate with at least a "low priority" alarm but continue to ventilate the patient with ambient air. Alarms for low or high expired volume should start as a "low priority" when falling outside user-defined limits and escalate to "medium priority" if condition worsens. ${ }^{[31]}$ The device should alert a blocked tube within two respiratory cycles or $5 \mathrm{~s}$ with at least a "medium priority" alarm. Monitoring of tube disconnection, a common occurrence due to several factors in ICU, is important. This can be done by measuring pressure in the expiratory limb, flow through exhalation valve, end-expiratory volume, or using end-tidal $\mathrm{CO}_{2}$ monitors.

\section{Oxygen monitoring}

This should measure oxygen concentration at the patient connection port or inspiratory limb either as an integral part or as an add-on before patient use. The high oxygen alarm should be of medium priority and the low oxygen alarm of high priority.

\section{Cleaning and disinfection}

The manufacturer should provide a detailed description of cleaning methodology to disinfect the device and its accessories before use in another patient. Filters at gas input point will avoid particles above $10 \mu \mathrm{m}$ from entering the system. A HEPA filter between the patient and expiratory limb of the ventilator should be used during the COVID-19 period.

\section{Software}

The standards for electronic components of the ventilator are governed by IEC 62304:2006 + AMD1:2015 and software running in the device should conform to "safety class C." Data collection, integration to the electronic medical record, and maintenance logs are desirable features to have in a ventilator but not mandated for an emergency ventilator. ${ }^{[33,34]}$

\section{Ventilators in the Making MIT E-vent}

It is a device being developed by MIT (USA) to be used in an emergency when conventional ventilators are unavailable or exhausted. This device automates the manual resuscitator Artificial Manual Breathing Unit (AMBU) bag (University of Minnesota, USA) using an open-source design and has basic monitoring such as tidal volume, inspiratory pressure, rate, and $\mathrm{I} / \mathrm{E}$ ratio. Additional support in the form of PEEP, PIP monitoring, and bacterial-viral filtration is also available. This ventilator can provide TV 200-800 ml, rate 6-40/ min, I: E of 1:1-1:4, and PEEP 5-15 $\mathrm{cmH}_{2} \mathrm{O}$. Safety features include maximum inspiratory pressure of $40 \mathrm{cmH}_{2} \mathrm{O}$, plateau pressure of $35 \mathrm{cmH}_{2} \mathrm{O}$, and manual clinician override. It provides an option to install a HEPA filter in an expiratory limb. It utilizes ambient air for gas delivery and does not require oxygen. This was developed at the University of Minnesota and is available from an open-source design instruction. ${ }^{[42]}$ Penlon Prima ESO2 Ventilators: These have been made under the Ventilator Challenge UK program and received approval by MHRA for use in NHS hospitals. ${ }^{[7]}$ Smiths paraPAC plus: This is a compact, light, and Magnetic resonance imaging-compatible ventilator designed for use even under extreme environmental conditions from Smiths medical products company. It provides invasive ventilation and supports continuous positive airway pressure. ${ }^{[43]}$ It has been approved under the Ventilator Challenge UK for use in this pandemic as announced on April 16, 2020. ${ }^{[7]}$ Engineers at National Aeronautics and Space Administration's (NASA) Jet Propulsion Laboratory developed a basic ventilator to tide over an unexpected demand in the current pandemic. Ventilator Intervention Technology Accessible Locally has been approved by physicians of the Icahn School of Medicine, New York, and FDA under an emergency use authorization. It was developed over 37 days and can be used for 3-4 months. ${ }^{[44]}$ Ventilators based on Ambu bag have been developed and approved by FDA (e.g., Virgin Atlantic) and provide for only discrete volume 
Varghese, et al.: ICU ventilators for COVID-19 pandemic

adjustments to be carried out by mechanical movement for adjusting the cam stroke. Other features on this ventilator are BPM and I/E ratio adjustment. PEEP pressure setting is achieved from the PEEP valve mounted on the Ambu bag. Inspiration pressure sensor warns against excess pressure or low pressure. ${ }^{[32]}$ In addition to established ventilator manufacturers, several engineers and design experts have contributing their expertise in open-source forums. These can then be taken up by prospective makers to produce ventilators using RepRap-class 3D printers and locally available materials. ${ }^{[45]}$ With aid of such technologies, a "public access ventilator" using a self-designed turbine and sensors has been purposed for use during an emergency. Furthermore, a proposal to use electric blowers instead of AMBU bags is being considered. ${ }^{[45]}$

\section{Indian Versions}

Several Indian manufacturers either alone or in collaboration with engineering institutes are developing ventilators for use during this crisis. They are using locally available components and providing basic functionality. How many will make it from the drawing board to the clinical arena needs to be seen. A few of them are summarized here. Indian Institute of Technology Roorkee (IIT Roorkee) along with All India Institute of Medical Sciences, Rishikesh, is developing a low-cost portable ventilator for COVID-19 patients named "Prana-Vayu" [IIT-Roorkee, India; Figure 2]. It incorporates remote monitoring, real-time spirometry, high-pressure alarms, and touch screen for monitoring parameters. ${ }^{[46]} \mathrm{AgVa}$ healthcare has developed an economical and energy-efficient ventilator [AgVa Advanced, $\mathrm{AgVa}$ Healthcare, India; Figure 3] with a variety of invasive and noninvasive modes, standard ventilator alarms, apnea detection with volume guaranteed backup, ability to run on ambient air or low-power oxygen, and a capacitive touch screen for monitoring and changing parameters. ${ }^{[47]}$ NOCCA Robotics Private Limited, an Indian Institute of Technology-Kanpur startup, is developing a ventilator called Nocca V110. It aims to provide pressure- and volume-control modes and noninvasive modes, both medical air/ambient air + oxygen usability, microprocessor-based control, inspiratory and expiratory filters, and remote control of device. ${ }^{[48]}$ Aerobiosys Innovations, Indian Institute of Technology Hyderabad startup, developed a portable ventilator, "Jeevan Lite." It can be run on rechargeable lithium-ion batteries

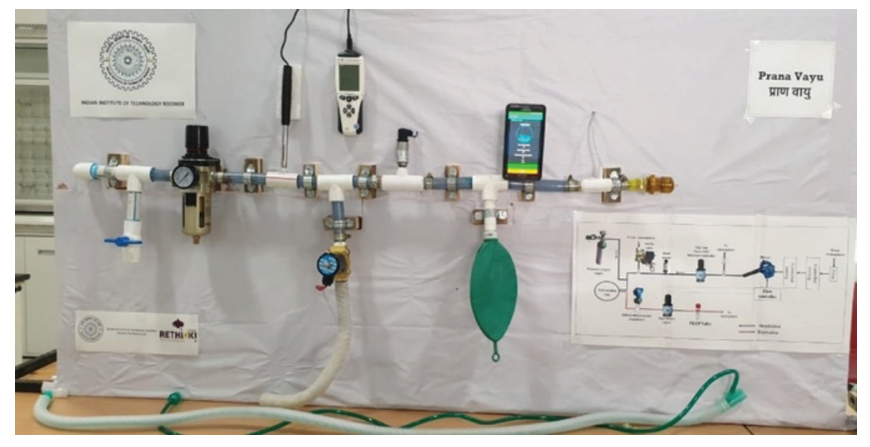

Figure 2: The "PRANA VAYU" (IIT-Roorkee, India) ventilator for up to $5 \mathrm{~h}$, offers a variety of invasive and noninvasive modes, and can be remotely operated through a phone app. ${ }^{[46]}$ By improving on the Bharucha ventilator and Mechanical Ventilator Milano, researchers at the Indian Institutes of Science Education and Research, Pune, are developing a low-cost ventilator with local components that can also be remotely accessed ${ }^{[49]}$ The Indian Railways are working on an economical ventilator prototype, Jeevan, based on automating the AMBU bag by using compressed air. It contains a portable compressor, a microprocessor-based controlling system, and basic settings of breathing rate, expiratory ratio, and tidal volume.$^{[50]}$ Ventilators developed by few agencies in the USA have been offered to Indian companies to be manufactured without a license fee. ${ }^{[42]}$ Sree Chitra Tirunal Institute for Medical Sciences and Technology in collaboration with Wipro 3D recently launched an AMBU bag-based device, AirBridge (Sree Chitra Institute of Medical Sciences and Wipro 3D, India) to meet emergency ventilation needs during the current pandemic [Figure 4]. This device was manufactured using locally available components and is designed to function as a bridge till a conventional ICU ventilator is available. ${ }^{[51]}$ Our team in association with engineers at Bharat Heavy Electronics Limited is working on a prototype for emergency ventilation by automating the Ambu bag.

\section{Challenges Faced by Indian Nonmedical Equipment Manufacturers in Developing Ventilators}

In the run-up to the COVID-19 situation in India, a call was given by the Prime Minister of India to Indian Industries at large to develop ventilators anticipating a serious shortfall in the event of hospitals being overwhelmed by sick patients. This has led to a situation where automobile companies, tractor manufacturers, heavy machinery manufacturers, and academic institutions took upon the task of ventilator development and manufacturing. One of the prerequisites for ventilator design is the knowledge on critical care needs and the patient-specific settings which are to be adjusted by critical care specialists.

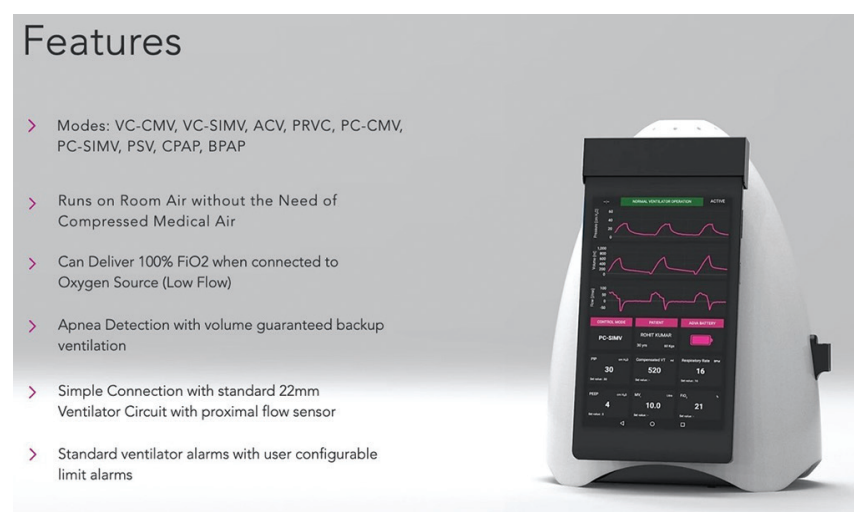

Figure 3: The AgVa (AgVa Healthcare, India) Advance ventilator. This is a portable low-cost ventilator that operates via a mobile phone. (Available at https://www.agvahealthcare.com/?gclid=EAlalQobChMI5fbTvZ-T6 gIVDb7ACh1NHAMMEAAYAiAAEgLjSfD_BwE) 


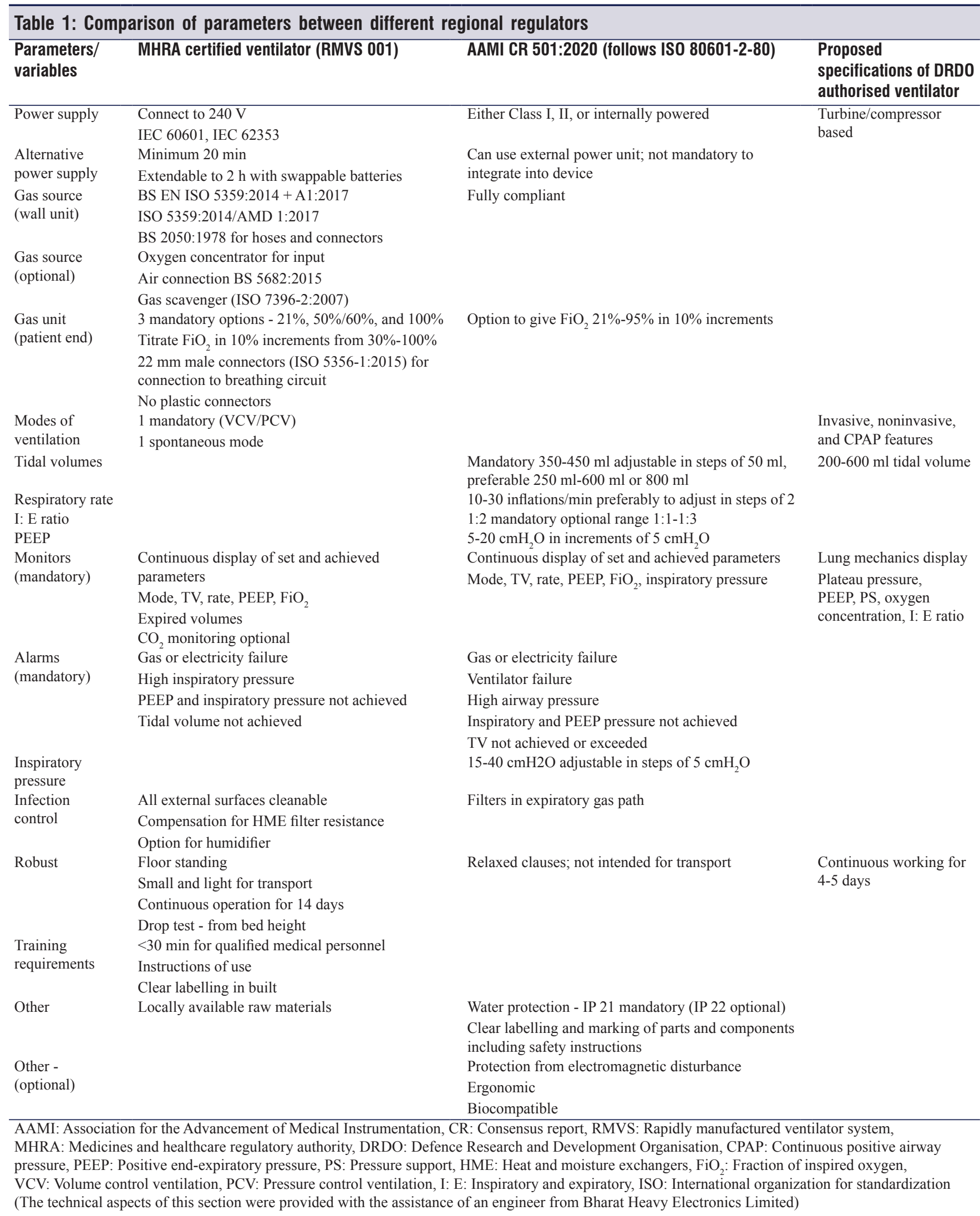

Unlike in certain countries like the UK and USA, revised guidelines for rapidly manufactured ventilators to meet the crisis under COVID-19 situation is not available and this paper tries to give broad guidelines to make the ventilator acceptable to critical care specialists and channelize the research and development (R\&D) efforts from Industry for 


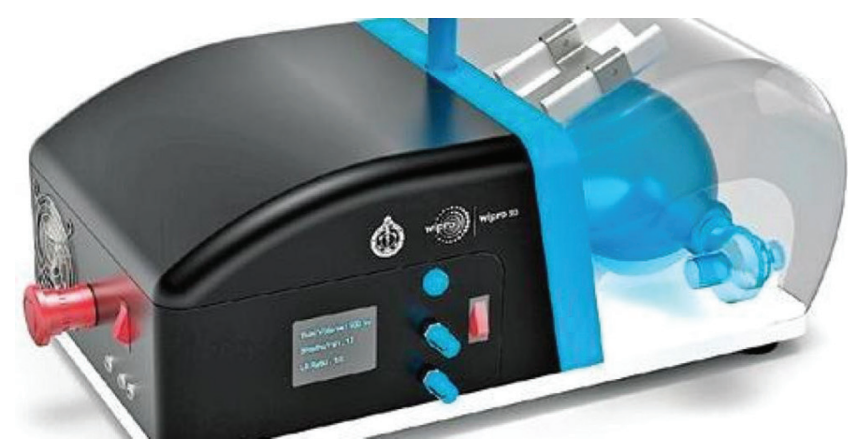

Figure 4: AirBridge (Sree Chitra Institute of Medical Sciences and Wipro 3D, India) Wipro-Chitra recently launched as a bridge till a conventional ventilator is available

fruitful realization of emergently manufactured ventilators.

Table 1 shows a comparison of various parameters from different regional regulators.

Parts required for ventilators have to be compatible for medical application with compatibility for oxygen which is corrosive against most metals and at the same time to be able to be autoclaved for ease of decontamination. Components such as pressure sensors and CT examination of confirmed SARS-CoV2 have found a mixed and diverse involvement of both lung parenchyma and interstitium. ${ }^{[8,9]}$ Findings can vary from predominantly peripheral involvement with ground-glass opacities in mild cases to patchy enlargement of opacities, consolidations, and "crazy paving appearance" in others. ${ }^{[8-10]}$ Often, there is a mismatch between radiological findings and clinical severity. Gattinoni et al. have described the existence of two phenotypes of COVID-19 lung, namely the Type-L and Type-H phenotypes. ${ }^{[11]}$ The most consistent clinical finding however is a severe hypoxic respiratory failure with histopathology showing diffuse alveolar damage. ${ }^{[12]}$ This heterogeneity is similar to previous descriptions of ARDS; ${ }^{[13-16]}$ hence, principles of treatment should also be similar with low tidal volume, constant driving pressure, optimum PEEP, and controlling inspiratory pressures to avoid aggravating the lung injury. ${ }^{[13,17-19]}$ All these developments point to the central role that a ventilator plays during mechanical ventilation. Hence when choosing a device for ventilation, it is mandatory that it performs as per the set parameters and not to accentuate an already damaged lung.

Sensors commonly used in the auto industry are not suitable for the ventilator application. Component suppliers for ventilators world over are flooded with orders and are not able to match the market demand. Many industries had to leverage their existing suppliers to develop sensors for inspiration and expiration circuits. Typically, 100 mbar sensor and 25 mbar sensor required had to be developed through such channels. Indigenous pressure sensor manufacturers have also come forward to develop such sensors and the challenge is in achieving the compact size and space constraints for the same. Proportional and direction control valves also pose a similar challenge in realizing the circuit. Attempts have been made by several agencies across the country to develop an Ambu bag-based ventilator by automating the Ambu bag operation as an emergency ventilator. While the Ambu bag provides inherent built-in features for safe operation like relief valve and PEEP valve and oxygen and air inlet, etc., the actuation mechanism becomes major factor in synchronizing the system when patient starts to breathe. Wherever cyclical operating mechanisms are used, it is hard to synchronize with the patient. This may be attempted with cam-based noncyclical actuation principle triggered from proximal flow sensors. Meditron, USA, had offered an ICU ventilator with all details including 3D models, drawings, component specifications, quality control documents, and testing protocols including software source code. This ventilator is based on a turbine for generating air source and design features not easy to manufacture. Industries attempting to develop ventilators need to study the applicable standards, have close interactions with critical care specialists, and keep track of the regulatory framework to ensure that the products developed meet the needs of the medical community.

\section{Conclusions}

While the governments in most countries are attempting to control the number of cases of COVID-19 at a given time by introducing lockdown measures, the health-care community has to be prepared to treat and provide ventilatory support to patients of SARS-CoV2 ARDS when necessary. In many countries, the need has been provided by standard available ventilators. In this manuscript, we have provided information about ways in which additional ventilators can be made available by using simple and locally available equipment and materials but have also outlined safety measures and alarms that need to be incorporated at a minimum for patient safety. It is hoped that such measures will not be required, but nonetheless, the medical community has to avail of all options when required and cooperation from local regulatory agencies for rapid approvals will be necessary.

\section{Financial support and sponsorship} Nil.

\section{Conflicts of interest}

There are no conflicts of interest.

\section{RefEREnCES}

1. Wang D, Hu B, Hu C, Zhu F, Liu X, Zhang J, et al. Clinical characteristics of 138 hospitalized patients with 2019 novel coronavirus-infected pneumonia in Wuhan, China. JAMA 2020;323:1061-9.

2. Guan WJ, Ni ZY, Hu Y, Liang WH, Ou CQ, He JX, et al. Clinical characteristics of coronavirus disease 2019 in China. N Engl J Med 2020;382:1708-20.

3. Coronavirus Update. COVID-19 Virus Pandemic-Worldometer. Available from: https://www.worldometers.info/coronavirus. [Last accessed on 2021 Apr 21].

4. Siow WT, Liew MF, Shrestha BR, Muchtar F, See KC. Managing COVID-19 in resource-limited settings: Critical care considerations. Crit Care 2020;24:167.

5. Wu Z, McGoogan JM. Characteristics of and important lessons from the coronavirus disease 2019 (COVID-19) outbreak in China: Summary of a report of 72314 cases from the Chinese center for disease control and prevention. J Am Med Assoc 2020;323:1239-42.

6. Augoustides JG. Critical care during the coronavirus crisis: challenges 
and considerations for the cardiothoracic and vascular anesthesia community. J Cardiothorac Vasc Anesth 2020;34:2299-302.

7. Ventilator Challenge UK. Ventilator Challenge UK Consortium. Available from: https://www.ventilatorchallengeuk.com. [Last accessed on $2020 \mathrm{Jul} 08]$.

8. Zhou S, Wang Y, Zhu T, Xia L. CT features of coronavirus disease 2019 (COVID-19) pneumonia in 62 patients in Wuhan, China. AJR Am J Roentgenol 2020;214:1287-94.

9. Li X, Fang X, Bian Y, Lu J. Comparison of chest CT findings between COVID-19 pneumonia and other types of viral pneumonia: A two-center retrospective study. Eur Radiol 2020;30:5470-8.

10. Li M, Lei P, Zeng B, Li Z, Yu P, Fan B, et al. Coronavirus disease (COVID-19): spectrum of CT findings and temporal progression of the disease. Acad Radiol 2020;27:603-8.

11. Gattinoni L, Chiumello D, Caironi P, Busana M, Romitti F, Brazzi L, et al. COVID-19 pneumonia: Different respiratory treatments for different phenotypes? Intensive Care Med 2020;46:1099-102.

12. Tian S, Hu W, Niu L, Liu H, Xu H, Xiao SY. Pulmonary pathology of early-phase 2019 novel coronavirus (COVID-19) pneumonia in two patients with lung cancer. J Thorac Oncol 2020;15:700-4.

13. Wilcox SR. Management of respiratory failure due to covid-19. BMJ 2020;369:m1786

14. Li X, Ma X. Acute respiratory failure in COVID-19: Is it "typical" ARDS? Crit Care 2020;24:198

15. Maunder RJ, Shuman WP, McHugh JW, Marglin SI, Butler J. Preservation of normal lung regions in the adult respiratory distress syndrome. Analysis by computed tomography. JAMA 1986;255:2463-5.

16. Gattinoni L, Pesenti A, Bombino M, Baglioni S, Rivolta M, Rossi F, et al. Relationships between lung computed tomographic density, gas exchange, and PEEP in acute respiratory failure. Anesthesiology 1988;69:824-32.

17. Raghavendran K, Napolitano LM. ALI and ARDS: Challenges and advances. Crit Care Clin 2011;27:429-37.

18. Terragni PP, Del Sorbo L, Mascia L, Urbino R, Martin EL, Birocco A, et al. Tidal volume lower than $6 \mathrm{ml} / \mathrm{kg}$ enhances lung protection: Role of extracorporeal carbon dioxide removal. Anesthesiology 2009;111:826-35

19. Gattinoni L, Marini JJ, Collino F, Maiolo G, Rapetti F, Tonetti T, et al. The future of mechanical ventilation: Lessons from the present and the past. Crit Care 2017;21:183.

20. Iyengar K, Bahl S, Raju Vaishya, Vaish A. Challenges and solutions in meeting up the urgent requirement of ventilators for COVID-19 patients. Diabetes Metab Syndr 2020;14:499-501.

21. Neyman G, Irvin CB. A single ventilator for multiple simulated patients to meet disaster surge. Acad Emerg Med 2006;13:1246-9.

22. Paladino L, Silverberg M, Charchaflieh JG, Eason JK, Wright BJ, Palamidessi $\mathrm{N}$, et al. Increasing ventilator surge capacity in disasters: Ventilation of four adult-human-sized sheep on a single ventilator with a modified circuit. Resuscitation 2008;77:121-6.

23. Branson RD, Blakeman TC, Robinson BR, Johannigman JA. Use of a single ventilator to support 4 patients: Laboratory evaluation of a limited concept. Respir Care 2012;57:399-403.

24. Tonetti T, Zanella A, Pizzilli G, Irvin Babcock C, Venturi S, Nava S, et al. One ventilator for two patients: Feasibility and considerations of a last resort solution in case of equipment shortage. Thorax 2020;75:517-9.

25. Herrmann J, Fonseca da Cruz A, Hawley ML, Branson RD, Kaczka DW. Shared ventilation in the era of COVID-19: A theoretical consideration of the dangers and potential solutions. Respir Care 2020;65:932-45.

26. Cook DC. Implementing shared ventilation must be scientific and ethical, or it risks harm. Br J Anaesth 2020;125:e181-3.

27. Prisma Health Introduces VESper. Available from: https://www. prismahealth.org/VESper. [Last accessed on 2020 Jun 11].

28. Lai BK, Erian JL, Pew SH, Eckmann MS. Emergency open-source three-dimensional printable ventilator circuit splitter and flow regulator during the COVID-19 pandemic. Anesthesiology 2020;133:246-8.

29. Summ O, Schute J, Byhahn C, Kahle T, Herrmann M, Schulte C, et al. COVID-19 pandemic: Structured expansion of ventilation capacities using home respirators. Anaesthetist 2020;69:323-30.

30. Beitler JR, Mittel AM, Kallet R, Kacmarek R, Hess D, Branson R, et al. Ventilator sharing during an acute shortage caused by the COVID-19 pandemic. Am J Respir Crit Care Med 2020;202:600-4

31. ISO 80601-2-12:2020(en). Medical Electrical Equipment-Part 2-12: Particular Requirements for Basic Safety and Essential Performance of Critical Care Ventilators. Available from: https://www.iso.org/obp/ ui\#tiso: std: iso: 80601:-2-12:ed-2:v1:en. [Last accessed on 2020 Jun 11].

32. Kdodge. FDA Authorizes First-of-Its-Kind, Low-Cost Ventilator Developed by University of Minnesota. University Relations; 2020. Available from: https:/twin-cities.umn.edu/ news-events/fda-authorizes-first-its-kind-low-cost-ventilatordeveloped-university-minnesota. [Last accessed on 2020 Jun 23].

33. AAMI Consensus Report. Emergency Use Ventilator (EMV) Design Guidance. AAMI/CR501:2020. Available from: www.aami.org/ docs/default-source/standardslibrary/200410_cr501-2020_rev1-2. pdf?sfvrsn=699e62b7_2. [Last accessed on 2020 Jun 11].

34. Rapidly Manufactured Ventilators System (RMVS). Available from: https://assets.publishing.service.gov.uk/government/uploads/system/ uploads/attachment_data/file/879382/RMVS001_v4.pdf.

[Last accessed on 2020 Jun 11].

35. Essential Tech features for Ventilators. Available from: https:// www.mohfw.gov.in/pdf/EssentialTechfeaturesforVentilators. pdf. [Lastaccessed on 2020 Jun 11].

36. Kacmarek RM. The mechanical ventilator: past, present, and future. Respir Care 2011;56:1170-80

37. Bone RC, Eubanks DH. The basis and basics of mechanical ventilation. Dis Mon 1991;37:321-406.

38. Chatburn RL. Classification of mechanical ventilators. Respir Care 1992;37:1009-25.

39. Chatburn RL. A new system for understanding mechanical ventilators. Respir Care 1991;36:1123-55.

40. MacIntyre N. Design features of modern mechanical ventilators. Clin Chest Med 2016;37:607-13.

41. MacIntyre NR, Day S. Essentials for ventilator-alarm systems. Respir Care 1992;37:1108-12.

42. Coventor Emergency Ventilator - Adult Manual Resuscitator Compressor-2020-295-University of Minnesota Office for Technology Commercialization. Available from: http://license.umn.edu/ technologies/2020-295_coventor-emergency-ventilator-adult-manualresuscitator-compressor. [Last accessed on 2020 Jun 23].

43. paraPAC Plus, Ventilation|Smiths Medical. Available from: https://www smiths-medical.com/en-us/products/ventilation/mechanical-ventilation/ ventilators/parapac-plus. [Last accessed on $2020 \mathrm{Jul} 08$ ].

44. RocketScientistsDevelopVentilatorforCOVID-19Patients.Default;2020. Available from: https://www.aami.org/news/news-detail/2020/05/05/ rocket-scientists-develop-ventilator-for-covid-19-patients. [Last accessed on 2020 Jun 11].

45. Pearce JM. A review of open source ventilators for COVID-19 and future pandemics. F1000Res 2020;9:218.

46. Avadhani R. IIT-H Start-up Develops Portable Ventilator-The Hindu. IIT-H Start-Up Develops Portable Ventilator; 2020. Available from: https://www.thehindu.com/news/cities/Hyderabad/ iit-h-start-up-develops-portable-ventilator/article31252291.ece. [Last accessed on 2020 Jun 11].

47. AgVa Healthcare. Available from: https://www.agvahealthcare.com/ covid-19. [Last accessed on 2020 Jun 11].

48. Available from: https://www.iitk.ac.in/new/innovations-on-covid-19. [Last accessed on 2020 Jun 11].

49. Fighting COVID-19: IISER, Pune physicists develop low-cost ventilator. Available from: https://news.careers360.com/fighting-covid19-iiser-pune-physicists-develop-low-cost-ventilator. [Last accessed on 2020 Jun 11].

50. Service TN. Rail Coach Factory Kapurthala Manufactures Under Rs 10,000 Ventilator Prototype. Tribuneindia News Service. Available from: https://www.tribuneindia.com/news/punjab/rail-coach-factory-kapurt hala-manufactures-under-rs-10-000-ventilator-prototype-66032. [Last accessed on 2020 Jun 11].

51. Sree Chitra Launches Emergency Breathing Aid for Covid Patients. Available from: https://www.newindianexpress.com/cities/ thiruvananthapuram/2020/jul/08/sree-chitra-launches-emergencybreathing-aid-for-covid-patients-2166785. html. [Last accessed on $2020 \mathrm{Jul} 14]$. 